\title{
SEX-RATIO SELECTION IN A BIVOLTINE THRIPS. I. CONDITIONAL SEX-RATIO MANIPULATION AND FITNESS VARIATION
}

\author{
Bernard J. Crespi ${ }^{1}$ \\ Museum of Zoology and Department of Biology, University of Michigan, \\ Ann Arbor, MI 48109-1079
}

\begin{abstract}
Females of the bivoltine thrips Elaphrothrips tuberculatus (Hood) (Insecta: Thysanoptera) produce broods of either all males (by viviparity) or all females (by oviparity). Measurements of the sex-allocation ratio, ecological and physiological conditions affecting male and female offspring body size, and correlates of the relative fitnesses of adult males and females in relation to size indicate that female parents tend to be viviparous (produce males) if their offspring will become relatively large adults, and that males gain more in fitness from large size than do females. However, the conditions that link sex allocation with offspring fitness differ between the spring and summer generations. In spring, when breeding is synchronous, 1) oviparous and viviparous females do not differ in body size, 2) females tend to be viviparous where the fungus upon which they feed is relatively dense and where their offspring will become relatively large adults, and 3 ) fungus density is highly correlated with male and female offspring size. In summer, when breeding is relatively asynchronous, 1) viviparous females are much larger than oviparous females early (but not late) in the season, 2) large viviparous females begin breeding earlier than smaller ones, 3) offspring developing earlier in the season become larger adults, and 4) a higher proportion of females are viviparous earlier than later. Field experiments and field collections show that the covariation among sex allocation, conditions, and fitness is not caused by differential mortality by size or sex. Differences between the spring and summer generations in the cues used by females to adjust offspring sex ratio may be caused by seasonal variation in the factors that affect offspring size. However, in both generations, females tend to produce sons only when their offspring will become relatively large adults, whereas daughters are produced regardless of offspring size. These data suggest that females of $E$. tuberculatus avoid production of males (the sex with higher variance in expected fitness) when the size of their offspring is relatively uncertain.
\end{abstract}

Received November 3, 1987. Accepted April 21, 1988

Since Fisher (1930) deduced that frequency-dependent selection equalizes parental expenditure on each sex, theoretical work on sex-allocation ratios has focused on quantifying Fisher's argument and elucidating the situations under which deviations from equal expenditure are expected to occur (Shaw and Mohler, 1953; Hamilton, 1967; Charnov, 1982; Nunney, 1985; Taylor, 1985; Frank, 1986, 1987a). These studies have demonstrated that sex-allocation ratios may be influenced by two sets of factors: relatedness effects, whereby competition, cooperation, and mating among a female's offspring influence the number of her genes transmitted to future generations (Hamilton, 1964a, 1964b, 1967; Clark, 1978; Taylor, 1981, 1988; Herre, 1985; Frank, 1986, 1987b, 1987c), and individual fitness effects, whereby behavioral, ecological, and demographic factors experienced

\footnotetext{
' Present address: School of Zoology, University of New South Wales, Kensington, N.S.W., Australia 2033.
}

by mothers and offspring differentially influence the ability of sons and daughters to transmit these genes (Trivers and Willard, 1973; Werren and Charnov, 1978; Bull, 1981; Charnov et al., 1981; Werren and Taylor, 1984; Grafen, 1986; Frank, 1987a). These two sets of factors, though conceptually distinct as levels of selection, may often jointly affect the sex-allocation ratio that females are selected to produce (e.g., Werren, 1984; Frank and Crespi, unpubl.).

Empirical studies have shown that the relatedness associated with subdivided populations affects sex ratios in the quantitative manner predicted by theory (Hamilton, 1979; Werren, 1980, 1983; Frank, 1985; Herre, 1985). In particular, sex ratios produced by females have been shown to covary with the expected relatedness of males competing for mates and with the degree to which a population is inbred. However, the evidence is less convincing for conditional sex-ratio manipulation in terms of individual offspring fitness (Myers, 1978; Williams, 
1979; Clutton-Brock and Iason, 1986; but see Clutton-Brock et al. [1984, 1986] and Burley [1986]). Detecting and measuring individual-level selection on the sex ratio is difficult, because three recalcitrant variables must be measured in field populations: 1) the sex-allocation ratio, which may differ considerably from the sex ratio (e.g., Boomsma and Isaaks, 1985), 2) the conditions experienced by mothers that indicate which sex-allocation ratio is favored by selection, and 3) the fitnesses of male and female offspring in relation to these conditions. In particular, to demonstrate that sexallocation ratios are adaptive, individual females must be shown to gain in fitness by producing certain sex-allocation ratios under certain conditions, and the mechanism of sex-allocation adjustment must be linked with the putative adaptive variation. Especially in vertebrates, which have no proven adaptive mechanism for sex-ratio adjustment, differential mortality by sex during development tends to obscure the empirical separation of adaptation from incidental effect or constraint.

Separating sex-ratio adaptation from incidental effect is easier when a known mechanism, such as haplodiploid sex determination, allows females to produce offspring of either sex facultatively. For this reason, many studies of sex ratios have been conducted on the haplodiploid insect order $\mathrm{Hy}-$ menoptera. However, insects of another order, the Thysanoptera or thrips, are also haplodiploid and show pronounced sex-ratio variation within and among species (Lewis, 1973; Hamilton, 1979; Ananthakrishnan, 1984; Crespi, 1987). Moreover, the mycophagous thrips show a variety of complex sexual and social behaviors, which often allow male and female fitnesses to be estimated in natural or laboratory populations (Crespi, 1986a, 1986b, 1987, 1988a, 1988b).

Elaphrothrips tuberculatus is a sporefeeding species of thrips in which males fight each other with their enlarged, armed forelegs in defense of individual egg-guarding females (Crespi, 1986b). Field observations, experiments, and collections show that large males win fights and defend females (Crespi, $1986 b, 1987)$. This strong sexual selection for large male body size creates a situation in which males may gain more in fitness from being relatively large than do females. As a result, a female parent should tend to produce sons if her offspring will become relatively large adults and daughters if her offspring will become small (Trivers and Willard, 1973; Charnov, 1982 pp. 37-66). The purpose of this paper is to test this hypothesis of adaptation to conditional sexratio selection, using field-collection data relating sex-allocation ratios and conditions to male and female fitnesses and experiments designed to falsify this and alternative hypotheses.

\section{Materials AND Methods \\ Elaphrothrips tuberculatus Life History and Behavior}

The life history and behavior of Elaphrothrips tuberculatus have been described in detail elsewhere (Crespi, 1986b, 1987, $1988 a$ ), and only relevant details are summarized here. Elaphrothrips tuberculatus is a winged thrips, about $5 \mathrm{~mm}$ long, that lives on clusters of hanging dead oak leaves (Quercus velutina and Q. rubra in Michigan) and feeds on spores of the ascomycete fungus Pseudomassaria polystigma (see Crespi [1986a, 1987], Stannard [1968], Lewis [1973], and Ananthakrishnan [1984] for information about thrips). This species overwinters in leaf litter as adults of both sexes, emerges in southern Michigan in mid-April to early May, and undergoes two generations per year. Adults that overwinter die in June, offspring born in spring breed during summer, and individuals born in both spring and summer may overwinter and breed the following spring.

Female offspring of $E$. tuberculatus are produced by oviparity, and male offspring are produced by viviparity (Crespi [1987] and Ananthakrishnan [1984] discuss other cases of facultative viviparity in thrips). At any one time, a female produces either all male or all female offspring. Oviparous females lay clutches of 10-60 eggs singly over periods of 1-3 weeks and guard their egg masses until the eggs hatch 1-2 weeks after completion of egg laying. Males guard gravid oviparous females on eggs for periods of from several hours to several days, and males usually switch between females at least once 
during breeding (Crespi, 1986b). Viviparous females produce $10-40$ first-instar larvae in any given generation and are not defended by males. In spring, individual females remain either oviparous or viviparous during the entire breeding period. However, in summer, when the breeding period is about twice as long as in spring, some females switch reproductive mode (Crespi, unpubl.).

\section{Field Collections}

Fieldwork was conducted in oak-hickory woodlands in Washtenaw County and Livingston County in southeastern Michigan. Leaf clusters containing Elaphrothrips tuberculatus were collected every few days during sampling periods, and clusters were collected as encountered, so that they would form a representative sample of the population.

Collections During Breeding. - During the breeding periods in spring (late April through early June) and summer (mid-July through mid-September), I recorded, for each leaf cluster a) numbers of males and females, b) male guarding status, c) female reproductive mode (viviparous or oviparous [see below]), d) whether or not oviparous females were guarding eggs, and e) numbers of eggs laid. Males and females were preserved in $70 \%$ ethanol, and femoral lengths of their forelegs were measured to the nearest 0.001 $\mathrm{mm}$ with an ocular micrometer. Femoral length of the forelegs is highly correlated with body length in males $(r=0.98)$ and females $(r=0.93)$ (Crespi, 1987). During the summer, field-collected second-instar larvae were reared to adulthood on small pieces of oak leaf in $9 \times 50-\mathrm{mm}$ petri dishes and sexed. Pupae collected during summer were allowed to develop into adults, after which they were sexed and femoral lengths of their forelegs were measured.

Collections of Spring Pupae. - For collections of pupal offspring of spring adults, leaf clusters were chosen on which at least $80 \%$ of the thrips either were in the pupal stage or were second-instar larvae (the last instar before pupation) that were as large as pupae. These leaf clusters containing pupae were kept in sealed plastic bags until the thrips had molted to adulthood 9-11 days later.
These adults were sexed and measured as described above.

\section{Measurements}

Measurement of Sex-Allocation Ratio.Because individual females produce either all female offspring (by oviparity) or all male offspring (by viviparity), the sex of a female's offspring can be determined by dissecting her and recording her reproductive mode, and an individual female can be considered as a unit of parental investment. The sex-allocation ratio is therefore equivalent to the proportion of females in each reproductive mode (see also Crespi [1987]). This allocation ratio differs from the secondary (birth) sex ratio because, as described below, viviparous and oviparous females differ in fecundity.

Measurement of Conditions. - Two conditions associated with sex-allocation ratio and offspring size were measured: 1) sizes of breeding oviparous and viviparous females (which is considered a measure of physiological conditions) and 2) ecological conditions correlated with offspring size. In spring, the ecological condition measured was the density of fruiting bodies (acervuli) of the fungus Pseudomassaria polystigma, which form round black dots on one surface of the oak leaves. Acervulus density was estimated by taking a $2.5 \times 2-\mathrm{cm}$ section from $1 \mathrm{~cm}$ to one side of the midrib of a leaf, placing the section between two glass slides under a compound microscope at $40 \times$ magnification, and adding the lengths of the intersection of the acervuli with a $2-\mathrm{mm}$ linear transect taken using an ocular micrometer (see Kendall and Moran [1963 p. 67] for an explanation of this method for estimating density). Since conversion to density units involves a simple linear scaling, the summed lengths of the transect intersections were used in the analyses. These fungus-density estimates were conducted both during the spring breeding period ( 10 transects per leaf) and for leaves that had contained groups of pupae that developed in spring (10 transects per leaf for two leaves). Fungus density could not be measured in summer, because the fungal acervuli are poorly developed. In summer, when both breeding and offspring development extend over a two-month period, time dur- 
ing summer was treated as an ecological condition associated with offspring size.

Measurement of Fitness Correlates. - For males, guarding status (i.e., whether or not a male was guarding a female when collected) during the spring breeding period was used as an estimate of fitness. Data from Crespi (1987) for 1983-1986 were used in this measurement along with data from 1987.

For females, number of eggs or first-instar larvae produced during the spring breeding period was used to estimate fitness. A high correlation between oviparous-female size and number of eggs laid has been reported elsewhere (Crespi, 1987) and is replicated here. The relationship between viviparous female size and number of larvae produced was investigated in the spring of 1987 by placing females in the field on clusters of 23 leaves from two large similar leaf clusters and allowing the females to feed and reproduce for 38 days. For the viviparous females, I counted the number of larvae that they had produced, dissected the females to count the number of embryos remaining in their abdomens, and added these two numbers. This method represents a compromise between mortality of larvae before counting (which was probably low) and my ability to count embryos and be confident that they would produce viable larvae.

\section{Experimental Tests}

Nested ANOVA. - In the spring of 1986 and 1987 , an experiment was conducted to investigate the covariation patterns among the reproductive mode of individual females, leaf conditions, and offspring size. The experimental design was a nested ANOVA, with male or female offspring size as the dependent variable and two nested grouping variables: 1) sets of 10-12 clusters of 2-3 leaves, with the leaf clusters in each set taken from different, large, field-collected leaf clusters and 2) individual leaf clusters within these sets. Nongravid females collected in the field in early spring were put on the clusters of leaves held together with plastic clips (one female per cluster), and the leaves were put in nylon bags suspended 1-2 $\mathrm{m}$ above ground in the woods. In 1986, 10 sets of 12 clusters were set up, and in 1987 , to increase sample size, 20 sets of 10 clusters were set up. These sets of leaves from the same leaf clusters represented sets of ostensibly similar ecological conditions. The null hypotheses for this experiment were that 1) male and female offspring sizes would not vary among or within sets of leaf clusters and 2) there would be no correlation (among the sets of leaf clusters) between the proportion of parent females in each reproductive mode and the average sizes (foreleg femoral lengths) of the male and female offspring developing on that set of leaf clusters. The nested-ANOVA variance components were similar among years, so data from both years were pooled.

Female and Offspring Size.-In midsummer 1986, the relationship between the size of a viviparous female and the average size of her male offspring was investigated by placing field-collected viviparous females individually in nylon bags containing two leaves from the same large leaf cluster, allowing them to reproduce for 55 days, and measuring the sizes of the females and their adult offspring.

\section{Analysis}

The field data on sex ratio and body size were analyzed at two levels: population-wide and among individual leaf clusters. The analyses at the level of leaf clusters are presented to show that population-wide variation is not due to effects from a small subset of leaf clusters. Because preliminary studies showed that sex ratio and offspring size change during summer, each half of the appropriate breeding or developmental period in summer was analyzed separately.

Statistics were computed using SAS (for the nested ANOVA; SAS Institute, 1985), and MIDAS (for the rest of the computations; Fox and Guire, 1976). The median test was used for analyzing the differences between groups that contained a high proportion of 0 and 1 values.

\section{RESULTS}

\section{Sex Allocation and Conditions}

Spring. - Viviparous (male-producing) and oviparous (female-producing) females did not differ in body size in spring (Table 1). The size variances of the two types of female were similar in 1986 , but viviparous 
TABLE 1. The sizes (foreleg femoral length $\pm \mathrm{SD}$, in $\mathrm{mm}$ ) of oviparous and viviparous females in spring, summer, and in each half of summer. Size variances were compared using Levene's test $(F)$. Sample sizes $(N)$ are numbers of thrips.

\begin{tabular}{|c|c|c|c|c|c|c|}
\hline \multirow[b]{3}{*}{ Season } & \multicolumn{4}{|c|}{ Reproductive mode } & \multirow[b]{3}{*}{$t$} & \multirow[b]{3}{*}{$F$} \\
\hline & \multicolumn{2}{|c|}{ Viviparous } & \multicolumn{2}{|c|}{ Oviparous } & & \\
\hline & $\bar{x} \pm \mathrm{SD}$ & $N$ & $\bar{x} \pm \mathrm{SD}$ & $N$ & & \\
\hline Spring 1986 & $0.443 \pm 0.032$ & 110 & $0.441 \pm 0.031$ & 335 & 0.6 & 0.01 \\
\hline Summer 1986 & $0.460 \pm 0.026$ & 337 & $0.443 \pm 0.034$ & 253 & $6.5^{* * * *}$ & $18.9^{* * *}$ \\
\hline First half & $0.462 \pm 0.024$ & 262 & $0.443 \pm 0.034$ & 154 & $6.8^{* * *}$ & $17.0^{* * *}$ \\
\hline Second half & $0.451 \pm 0.041$ & 75 & $0.445 \pm 0.036$ & 99 & 1.2 & 2.1 \\
\hline Spring 1987 & $0.450 \pm 0.034$ & 206 & $0.447 \pm 0.030$ & 712 & 1.3 & $5.2^{*}$ \\
\hline
\end{tabular}

$* P<0.05 ; * * P<0.001$.

females were more variable in size in 1987. For leaf clusters with at least one oviparous female and one viviparous female, viviparous females were larger than oviparous females on $50 \%$ ( 25 of 50 ) of the leaf clusters in $1986\left(X^{2}=0.0\right.$, d.f. $\left.=1, P>0.05\right)$ and on $58 \%$ (53 of 92) of the leaf clusters in 1987 $\left(X^{2}=1.1\right.$, d.f. $\left.=1, P>0.05\right)$.

The proportion of females on a leaf cluster that were viviparous was positively correlated with fungus density (Spearman's rank correlation, $r_{\mathrm{s}}=0.14, \mathrm{~N}=265$ leaf clusters, $P<0.05$ ). Because a high proportion of leaf clusters contained only oviparous females, I also compared fungus density on clusters that did or did not contain at least one viviparous female. Fungus density was higher where at least one female was viviparous $(\bar{x}$ $\pm \mathrm{SD}=124 \pm 40$ [units arbitrary], $N=$ 108 clusters), than where all females were oviparous $(\bar{x} \pm \mathrm{SD}=111 \pm 39, N=157$; $t=2.8, P<0.01)$.

Summer. - Viviparous females were substantially larger than oviparous females in summer, and viviparous females were also much less variable in size (Table 1). Viviparous females were larger than oviparous females on $53(73 \%)$ of the 70 leaf clusters on which at least one of each type of female was present $\left(X^{2}=7.3\right.$, d.f. $\left.=1, P<0.01\right)$. This association between large size and viviparity held only during the first half of the summer breeding period; during the second half, the difference between viviparous-female size and oviparous-female size was much smaller and nonsignificant. Viviparous females were larger than oviparous females on $35(80 \%)$ of 44 leaf clusters in the first half of the summer $\left(X^{2}=7.7, d . f .=1\right.$, $P<0.01$ ), and on $16(62 \%)$ of 26 leaf clus-
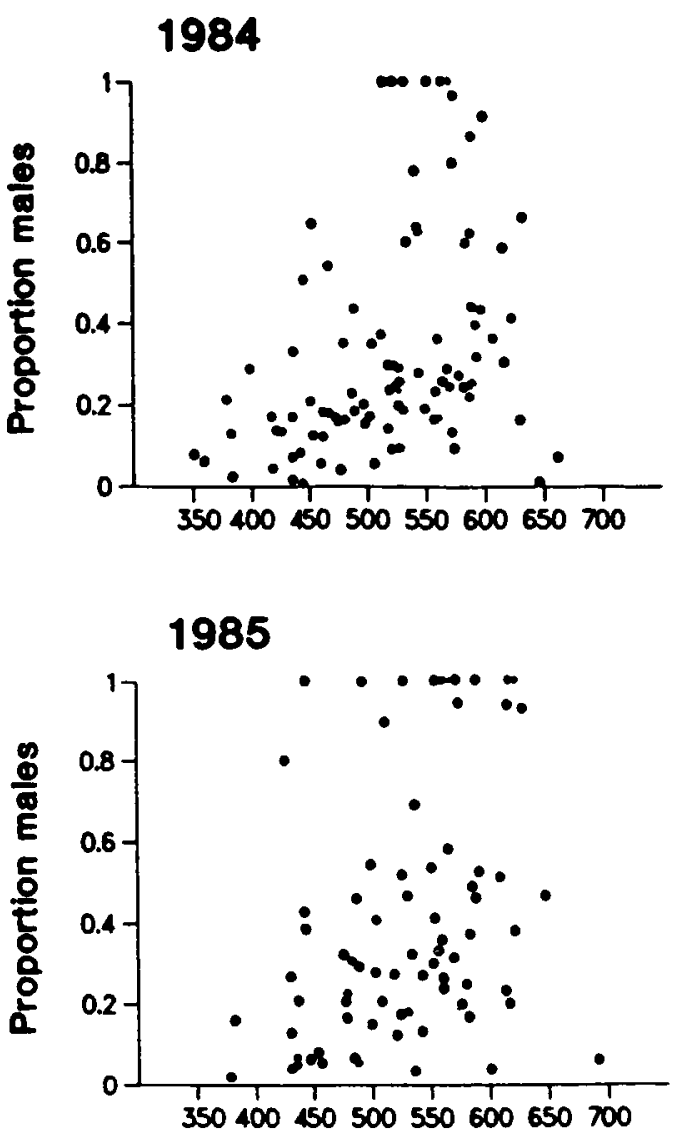

Average male offspring size

FiG. 1. The average size (foreleg femoral length, in $\mathrm{mm} \times 10^{3}$ ) of male Elaphrothrips tuberculatus collected as pupae at the end of the spring generation, in relation to the sex ratio of offspring on the leaf clusters. Each point represents a separate leaf cluster that contained the offspring of from 1-21 females. The correlation between average male offspring size and sex ratio is also highly significant when both variables are transformed to natural logarithms (1984: $r=0.41, P<$ $0.0001 ; 1985: r=0.40, P<0.001)$. 
TABLE 2. Product-moment correlations between proportion males (PM), average male size (MS), average female size (FS), female survivorship from the egg stage to the pupal stage (SV), and acervulus (fungus) density (AD) among leaf clusters containing Elaphrothrips tuberculatus collected as pupae at the end of the spring generation. Female survivorship was estimated by dividing the number of female pupae by the total number of hatched and unhatched eggs on the leaf cluster. Average female size and acervulus density were not measured in 1985. Sample sizes, which represent numbers of leaf clusters, are in parentheses.

\begin{tabular}{|c|c|c|c|c|c|c|}
\hline \multirow[b]{2}{*}{ Trait } & \multicolumn{4}{|c|}{1984} & \multicolumn{2}{|c|}{1985} \\
\hline & PM & MS & FS & SV & $\mathbf{P M}$ & MS \\
\hline MS & $\begin{array}{l}0.48^{* * * *} \\
(101)\end{array}$ & - & & & $\begin{array}{l}0.39 * * * \\
(78)\end{array}$ & - \\
\hline FS & $\begin{array}{l}0.34^{* *} \\
(127)\end{array}$ & $\begin{array}{l}0.75^{* * * *} \\
(91)\end{array}$ & - & & - & - \\
\hline SV & $\begin{array}{c}-0.35^{* * * *} \\
(108)\end{array}$ & $\begin{array}{r}-0.18 \\
(75)\end{array}$ & $\begin{array}{r}-0.19 \\
(99)\end{array}$ & - & $\begin{array}{c}-0.22^{*} \\
(121)\end{array}$ & $\begin{array}{r}-0.31 \\
(39)\end{array}$ \\
\hline $\mathrm{AD}$ & $\begin{array}{c}0.18^{*} \\
(141)\end{array}$ & $\begin{array}{l}0.39^{* * *} \\
(98)\end{array}$ & $\begin{array}{l}0.45^{* * *} \\
(126)\end{array}$ & $\begin{array}{r}-0.09 \\
(106)\end{array}$ & - & - \\
\hline
\end{tabular}

$* P<0.05 ; * * P<0.01 ; * * * P<0.001$.

ters in the second half $\left(X^{2}=0.7\right.$, d.f. $=1$, $P>0.05$ ).

Population-wide, a higher proportion of breeding females were viviparous during the first half of the summer $(63 \%)$ than during the second half $\left(43 \% ; X^{2}=20.0, d . f .=1, P\right.$ $<0.001$; Table 1). Among individual leaf clusters, the average proportion of females that were viviparous was also higher in the first half of the summer $(\bar{x} \pm \mathrm{SD}=0.57 \pm$ $0.31, N=76$ clusters) than in the second half $(\bar{x} \pm \mathrm{SD}=0.42 \pm 0.39, N=61$; median test, $P<0.01)$.

\section{Offspring Sex Ratio, Conditions, and Offspring Size}

Spring. - In 1984 and 1985, there were strong positive correlations between the average size of males that developed on a leaf cluster and the proportion of pupae that were males (Table 2). Figure 1 shows that average male size and sex ratio were correlated primarily because few leaf clusters contained a high proportion of males that were small; in both years, the variance in sex ratio was lower for groups of males below the average size (1984: $s^{2}=0.034, N=46$ clusters, 1985 : $\left.s^{2}=0.072, N=36\right)$, than for groups of males above the average size (1984: $s^{2}=0.093, N$ $=55 ; 1985: s^{2}=0.110, N=42$; nonparametric Levene tests, $P<0.05$ in each year). Fungus density was also positively correlated with sex ratio, average male size, and average female size, and average female size was correlated with average male size and sex ratio. Female survivorship from egglaying to the pupal stage was uncorrelated with average male size, average female size, or fungus density but was negatively correlated with sex ratio in both years. This correlation was probably caused by factors, such as egg cannabilism and parasitoid wasps, that affect female survivorship independently of male survivorship (Crespi, unpubl.).

Summer. - Population-wide, male and

TABLE 3. The sizes (foreleg femoral length $\pm \mathrm{SD}$, in $\mathrm{mm}$ ) of adult Elaphrothrips tuberculatus males and females collected as pupae during each half of the summer generation and the numbers of males and females collected as second-instar larvae and reared to adulthood. Sample sizes $(N)$ are numbers of thrips.

\begin{tabular}{|c|c|c|c|c|c|c|c|}
\hline \multirow[b]{3}{*}{ Sex and stage } & \multicolumn{5}{|c|}{1985} & \multirow{2}{*}{\multicolumn{2}{|c|}{$\frac{1986}{\text { First half }}$}} \\
\hline & \multicolumn{2}{|l|}{ First half } & \multicolumn{2}{|l|}{ Second half } & \multirow[b]{2}{*}{1} & & \\
\hline & $\bar{x} \pm$ SD & $N$ & $x \pm$ SD & $N$ & & $x \pm \mathrm{SD}$ & $N$ \\
\hline Male pupae & $0.565 \pm 0.063$ & 277 & $0.489 \pm 0.067$ & 58 & $8.3^{* * *}$ & $0.560 \pm 0.068$ & 457 \\
\hline Male larvae & - & 299 & - & 162 & - & - & 950 \\
\hline Female pupae & $0.451 \pm 0.023$ & 98 & $0.427 \pm 0.029$ & 50 & $5.5^{* *}$ & $0.445 \pm 0.024$ & 408 \\
\hline Female larvae & - & 126 & - & 177 & - & - & 658 \\
\hline
\end{tabular}

$* P<0.01 ; * * P<0.001$. 
female offspring that were collected as pupae during the first half of the summer became substantially larger adults than those collected in the second half (Table 3 ). Similarly, among leaf clusters, the average size of males collected as pupae was higher in the first half of the summer than in the second half in 1985 and 1986 (Table 4). The average size of females collected as pupae was higher during the first half of the summer in 1985, but this difference was nonsignificant in 1986. In addition, the average sizes of male and female offspring covaried among leaf clusters in 1985 (product-moment correlation, $r=0.61, N=17, P<$ $0.01)$ and $1986(r=0.61, N=46, P<$ $0.001)$. This correlation indicates that male and female offspring size are affected in a similar way by local environmental factors.

These declines in offspring size during summer coincided with decreases in offspring sex ratio. For offspring collected as second-instar larvae, the population-wide sex ratio (proportion males) was more malebiased in the first half of the summer than in the second half in $1985\left(X^{2}=39.2, d . f\right.$. $=1, P<0.001)$ and in $1986\left(X^{2}=22.6\right.$, d.f. $=1, P<0.001$ ) (Table 3). This summer decline in population-wide sex ratio was similar for offspring collected as pupae in $1985\left(X^{2}=15.1\right.$, d.f. $\left.=1, P<0.001\right)$ and in $1986\left(X^{2}=37.1\right.$, d.f. $\left.=1, P<0.001\right)$. Among leaf clusters, the average sex ratio of collected second-instar larvae was more male-biased in the first half of the summer than in the second half in 1985 and 1986 (Table 5). For offspring collected as pupae, the average sex ratio among leaf clusters was higher early in summer in 1986 but not in 1985.

To investigate a possible cause of both the size difference between viviparous and

TABle 3. Extended.

\begin{tabular}{ccc}
\hline \multicolumn{3}{c}{1986} \\
\hline Second half \\
\hline$x \pm$ SD & $N$ & $t$ \\
\hline $0.487 \pm 0.070$ & 192 & $12.4^{* * *}$ \\
- & 185 & - \\
$0.432 \pm 0.027$ & 342 & $7.1^{* *}$ \\
- & 219 & - \\
\hline
\end{tabular}

oviparous females in early summer and the summer decline in the proportion of females that was viviparous, I collected two large leaf clusters in the field in the early summer of 1987 and dissected the females. The viviparous females were then divided into four groups according to the developmental stage of their most highly developed embryo ( 4 = fully developed, $3=$ rounded with eyespots, 2 = rounded without eyespots, 1 = elongate without eyespots). I then measured the sizes of the females and computed the correlations between female size and embryo stage. For both clusters, large viviparous females contained more highly developed embryos than did smaller ones (product-moment correlation: $r=0.45, N$ $=46, P<0.01 ; r=0.69, N=21, \mathrm{P}<$ $0.001)$. These data suggest that larger viviparous females begin producing offspring earlier in summer than do smaller viviparous females. In addition, on the leaf cluster where oviparous females were also present, these oviparous females were smaller $(\bar{x} \pm$ $\mathrm{SD}=0.442 \pm 0.015, N=9)$ than the viviparous females $(\bar{x} \pm \mathrm{SD}=0.468 \pm 0.022$, $N=46$; Mann-Whitney $U$ test, $P<0.01$ ).

I tested the hypothesis that large oviparous females begin breeding earlier than smaller ones by comparing, for the first ten days of the summer in 1987 , the sizes of females that were guarding eggs $(\bar{x} \pm \mathrm{SD}=$ $0.442 \pm 0.030 \mathrm{~mm}, N=45$ ) with the sizes of oviparous females that had not yet laid eggs $(\bar{x} \pm \mathrm{SD}=0.442 \pm 0.035 \mathrm{~mm}, N=$ 15). For oviparous females, large individuals apparently did not begin breeding relatively early $(t=0.02, P>0.05)$.

\section{Male and Female Fitness Correlates and Body Size}

The relationship between male size and the probability that a male was guarding a female when collected is shown in Figure 2, for the years 1983-1987. These plots are similar in shape and elevation to a plot of male size versus the proportion of 100 hourly scan samples during which a male was guarding a female, derived from a longitudinal study of 18 individually marked males on a single large leaf cluster in the spring of 1984 (Crespi, $1986 b$ fig. 4). The agreement between these sets of data suggests that the field measurements conducted over five 
TABLE 4. The average sizes (foreleg femoral length $\pm \mathrm{SD}$, in $\mathrm{mm}$ ) among leaf clusters of adult Elaphrothrips tuberculatus males and females collected as pupae during each half of the summer generation. Sample sizes ( $N$ ) are numbers of leaf clusters.

\begin{tabular}{|c|c|c|c|c|c|c|}
\hline \multirow[b]{2}{*}{ Sex } & \multirow[b]{2}{*}{ Year } & \multicolumn{2}{|c|}{ First half } & \multicolumn{2}{|c|}{ Second half } & \multirow[b]{2}{*}{$t$} \\
\hline & & $\bar{x} \pm$ SD & $N$ & $\bar{x} \pm \mathrm{SD}$ & $N$ & \\
\hline Male & $\begin{array}{l}1985 \\
1986\end{array}$ & $\begin{array}{l}0.549 \pm 0.056 \\
0.553 \pm 0.056\end{array}$ & $\begin{array}{l}29 \\
57\end{array}$ & $\begin{array}{l}0.486 \pm 0.055 \\
0.510 \pm 0.051\end{array}$ & $\begin{array}{l}21 \\
25\end{array}$ & $\begin{array}{l}4.0^{* * * *} \\
3.3^{* *}\end{array}$ \\
\hline Female & $\begin{array}{l}1985 \\
1986\end{array}$ & $\begin{array}{l}0.444 \pm 0.015 \\
0.443 \pm 0.020\end{array}$ & $\begin{array}{l}12 \\
40\end{array}$ & $\begin{array}{l}0.423 \pm 0.021 \\
0.433 \pm 0.021\end{array}$ & $\begin{array}{l}10 \\
21\end{array}$ & $\begin{array}{l}2.7^{*} \\
1.9\end{array}$ \\
\hline
\end{tabular}

$* P<0.05 ; * * P<0.01 ; * * * P<0.001$.

years accurately reflect the covariation between male size and mating success.

Figure 3 shows the regressions of numbers of young produced on female size for oviparous females $(y=159 x-27.0, \mathrm{SE}$ of regression coefficient $=27, N=146, P<$ $\left.0.001, r^{2}=0.20\right)$ and viviparous females $(y$ $=161 x-50.7, \mathrm{SE}$ of regression coefficient $=27, N=20, P<0.001, r^{2}=0.67$ ) in spring. The slopes of the regressions were similar (one-way ANCOVA, $F_{[1,162]}=0.00, P>$ 0.50 ), but the regressions differed in elevation $\left(F_{[1.162]}=124.9, P<0.001\right)$.

To assess directly the covariation between male and female body size and fitness, the slopes of the regressions of relative fitness (absolute fitness divided by mean fitness) on body size were compared between the sexes, using the collection data for oviparous females from 1987 and the scan sample data for males from 1984. The slope was significantly steeper for males $(b=0.0073$, $\mathrm{SE}=0.0019, N=18)$ than for females $(b$ $=0.0035, \mathrm{SE}=0.0006, N=146$; one-way ANCOVA, $\left.F_{[1,160]}=10.0, P<0.01\right)$. The analysis gave similar results with male and female body sizes standardized to a mean of zero and a variance of one (Fig. 4). Thus, if spring guarding success and number of young produced are accurate estimates of lifetime reproductive success for males and females, then males gain more in fitness from large size than do females.

\section{Experimental Tests}

Nested-ANOVA Experiment. - This experiment was designed to test the hypothesis that, in spring, variation in conditions among leaf clusters affects the sex-allocation ratio (female reproductive mode) and offspring size. For both male and female offspring, there was significant variation in offspring size among sets of leaf clusters (males: $F_{[27,49]}=7.4, P<0.001$; females: $F_{[29,152]}$ $=71.1, P<0.001)$. Within sets of leaf clusters, groups of female offspring varied in size $\left(F_{[152,1,112]}=10.1, P<0.001\right)$, but groups of male offspring did not $\left(F_{[49,375]}=1.1, P\right.$ $>0.05)$. These data indicate that, for offspring of both sexes, conditions affecting sizes vary among sets of leaf clusters and that, for female offspring, conditions vary among leaves from the same leaf cluster. This variation among and within leaf clusters suggests that offspring size may be somewhat predictable for female parents. In addition, there was a strong positive correlation among sets of leaf clusters between the average sizes of male and female offspring (product-moment correlation, $r=$ $0.83, P<0.001)$. This correlation indicates that male and female offspring sizes are affected similarly by variation in leaf quality.

The relationships between the proportion of females that were viviparous on a set of leaf clusters and the average sizes of male

TABLE 5. The average sex ratio (proportion males $\pm \mathrm{SD}$ ) among leaf clusters containing Elaphrothrips tuberculatus collected as second-instar larvae and pupae. Sample sizes $(N)$ are numbers of leaf clusters.

\begin{tabular}{|c|c|c|c|c|c|c|}
\hline \multirow[b]{2}{*}{ Stage collected } & \multirow[b]{2}{*}{ Year } & \multicolumn{2}{|c|}{ First half } & \multicolumn{2}{|c|}{ Second half } & \multirow[b]{2}{*}{$P$ (median test) } \\
\hline & & $x \pm$ SD & $N$ & $\bar{x} \pm$ SD & $N$ & \\
\hline $\begin{array}{l}\text { Second-instar } \\
\text { larvae }\end{array}$ & $\begin{array}{l}1985 \\
1986\end{array}$ & $\begin{array}{l}0.81 \pm 0.31 \\
0.65 \pm 0.35\end{array}$ & $\begin{array}{l}39 \\
87\end{array}$ & $\begin{array}{l}0.53 \pm 0.46 \\
0.40 \pm 0.42\end{array}$ & $\begin{array}{l}38 \\
40\end{array}$ & $\begin{array}{l}<0.05 \\
<0.01\end{array}$ \\
\hline Pupae & $\begin{array}{l}1985 \\
1986\end{array}$ & $\begin{array}{l}0.83 \pm 0.29 \\
0.63 \pm 0.38\end{array}$ & $\begin{array}{l}31 \\
66\end{array}$ & $\begin{array}{l}0.75 \pm 0.35 \\
0.47 \pm 0.42\end{array}$ & $\begin{array}{l}24 \\
31\end{array}$ & $\begin{array}{c}\text { ns } \\
<0.05\end{array}$ \\
\hline
\end{tabular}




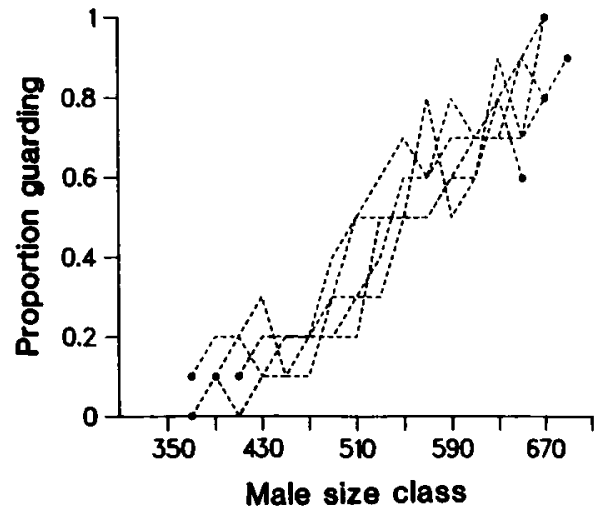

FIG. 2. The relationship between Elaphrothrips tuberculatus male size (foreleg femoral length, in $\mathrm{mm}$ $\times 10^{3}$, in size classes of $0.020 \mathrm{~mm}$ ) and the proportion of males in that size class that were guarding females when collected. Each dashed line represents data from a different year.

and female offspring is shown in Figure 5. There was a significant positive correlation between average female offspring size and the proportion of female parents that were viviparous (product-moment correlation, $r$ $=0.40, P<0.05, N=30$ ), and this correlation approached significance for male offspring ( $r=0.30, P=0.12, N=28)$. Comparison of Figure 5 with Figure 1 shows that, both in this experiment and in the field, a relatively low proportion of females were viviparous on leaf clusters where their offspring became relatively small adults.

Female and Offspring Size Experiment. - In summer, there was a significant correlation between viviparous female size and the average size of her male offspring (product-moment correlation, $r=0.53, N$ $=30$ female parents, $N=240$ total males, $P<0.01$ ). This relationship apparently was not influenced by offspring number; there was no correlation between average male size and number of males that developed on a leaf cluster $(r=0.15, P>0.40)$.

\section{DISCUSSION}

Sex Allocation, Conditions, and Fitness in Elaphrothrips tuberculatus

The field data indicate that 1) the sexallocation ratio (the proportion of females in each reproductive mode) and larval and pupal sex ratio are positively correlated with the physiological and ecological conditions associated with large offspring size, and 2)

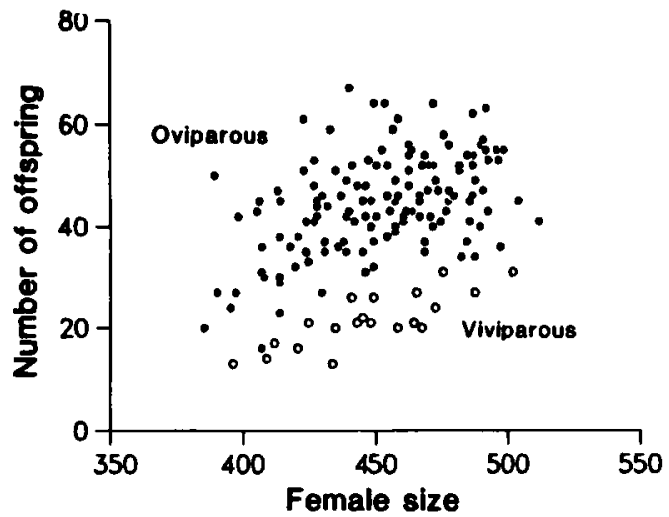

FIG. 3. The relationships between viviparous and oviparous female size (foreleg femoral length, in $\mathrm{mm}$ $\times 10^{3}$ ) and fecundity (numbers of first-instar larvae or eggs produced, respectively).

males gain more in fitness from large size than do females. Female Elaphrothrips tuberculatus therefore tend to produce the sex that gains most in fitness from developing under local conditions (see also CluttonBrock et al. [1984, 1986]). However, the cues used by females to adjust sex allocation differ substantially between the spring and summer generations.

In spring, viviparous and oviparous females did not differ in body size. However, fungus density was positively correlated with

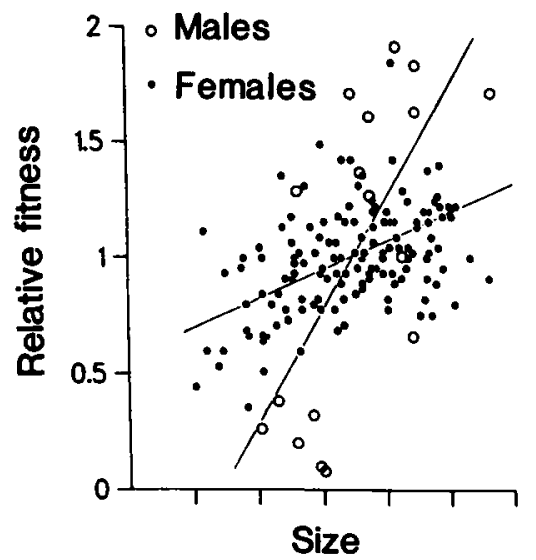

FIG. 4. The relationships between body size and estimated relative fitness for males and females of Elaphrothrips tuberculatus. Male and female body sizes are standardized separately to a mean of zero and a variance of one. The slope was significantly higher for males than for females regardless of whether the untransformed data (see text) or the size-standardized data was used (one-way ANCOVA, $F_{[1,160]}=33.5, P$ $<0.001$ ). 


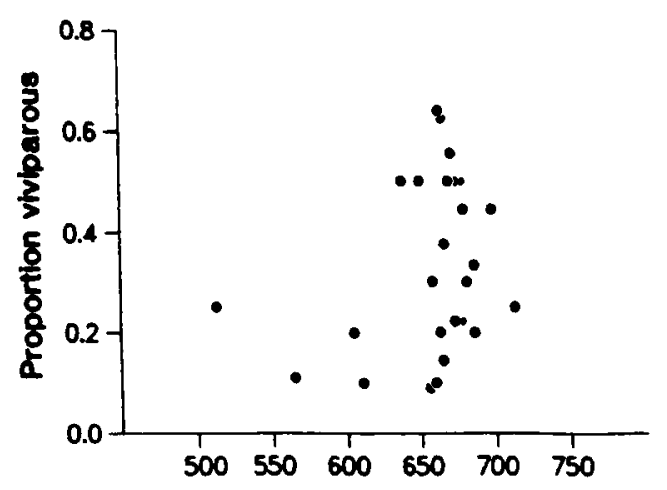

Average male offspring size

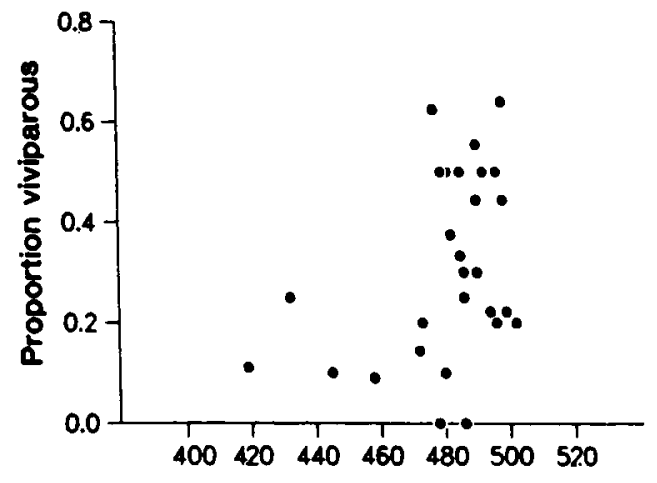

Average female offspring size

FIG. 5. The average sizes (foreleg femoral length, in $\mathrm{mm} \times 10^{3}$ ) of male and female offspring from experimental sets of leaf clusters, in relation to the proportion of female parents on that set of leaf clusters that was viviparous. See text for details. The correlation between average offspring size and proportion viviparity is also significant for females when both variables are transformed to natural logarithms (females: $r=0.53, P<0.01$; males: $r=0.33, P=0.09$ ). This plot should be compared to Figure 1 .

female reproductive mode, pupal offspring sex ratio, and adult offspring size. These data indicate that females detect some environmental condition correlated with the quality of fungal food on a leaf cluster and tend to be viviparous (produce males) where feeding conditions are good and where their offspring will develop into relatively large adults. An alternative explanation, that most or all of the developing males die on poor leaf clusters where they would have become small adults, is unlikely because 1) the nested-ANOVA experiment shows that the sexallocation ratio is associated with leaf conditions and offspring size in the same way in this experiment as in the field and 2) the proportion of females that were viviparous was positively correlated with fungus density in the field.

In early summer, viviparous females were much larger than oviparous females and were also much less variable in size. A simple explanation for this size difference is that, early in summer, relatively large females were viviparous rather than oviparous because these large females are able to produce offspring earlier than smaller viviparous females, and offspring produced earlier in summer develop into larger adults. This hypothesis is consistent with the field data relating viviparous female size to embryonic offspring stage and the experimental data showing a positive correlation between the size of viviparous females and the size of their adult male offspring. The quantitative relationship between reproductive timing and adult size of offspring for viviparous females in the field is unknown. However, laboratory observations of viviparous females in summer suggest that the difference in time of initial offspring production between females with fully developed embryos and those with elongate viviparous ovaries is probably about two weeks. Assuming a two-week difference throughout offspring development, the regression of the size of males collected in summer 1986 as pupae on collection date $(y=602.9-2.97 x$, $r=-0.49, P<0.001)$ predicts a size difference (foreleg femoral length) over this time of about $0.045 \mathrm{~mm}$ for male offspring. If these estimates are correct, then this difference in timing may have substantial effects on male-offspring size and subsequent fitness (Fig. 2). The observed summer decline in offspring size may also explain in part why the sex-allocation ratio and the larval and pupal sex ratios are more malebiased during the first half of summer than during the second half.

Seasonal variation in the factors that affect adult size of offspring may cause the differences between spring and summer in the measured correlates of the cues used by females to adjust offspring sex ratio. Thus, in spring, when breeding is synchronous, offspring-size variation is influenced by spatial variation in leaf quality. By contrast, in summer, when breeding is relatively asyn- 
chronous, offspring size is affected by factors that vary temporally and that interact with viviparous female size. These findings suggest that studies focusing on single conditions associated with the sex-allocation ratio may give incomplete or misleading results.

The spring data relating male size to mating success and female size to numbers of offspring produced suggest that males gain more in fitness from large size than do females. However, lifetime reproductive success depends also on survivorship and summer breeding. For example, because the intensity of sexual selection for large male body size depends on the population-wide sex ratio (Crespi, 1987), male fitness may depend more on size during spring (when the population-wide adult sex ratio is about $40 \%$ male) than during summer (when the adult sex ratio is about $20 \%$ male) (Crespi, 1987). Conversely, the large size of viviparous females relative to oviparous females in early summer suggests that female fitness depends more on size in summer than in spring. Despite these qualifications, spring breeding probably provides good estimates of lifetime reproduction, because: 1) males and females born in both spring and summer may breed in the following spring; 2) the number of offspring produced per adult is generally much higher in spring than in summer (for example, in the summer of 1984 , when a drought occurred, virtually no offspring were produced [Crespi, unpubl.]); and 3) the proportion of breeding females that is viviparous is much higher in summer (56\%) than in spring (25\%), and viviparous females are irrelevant to male reproductive success because thrips are haplodiploid.

\section{How Does Sex-Ratio Selection Affect Fitness?}

Sex-ratio theory for patchy environments with differential effects on male versus female fitness predicts a threshold between the production of either all males or all females; in any given patch, females should produce only the sex that gains most in fitness from developing under local conditions (Charnov et al., 1981; Bull, 1981; see also Frank [1987a]). However, Charnov (1982 pp. 40-42) pointed out that a gradual shift in sex-allocation ratio with conditions is more likely to be recorded than a sharp threshold, because animals adjusting their sex-allocation ratios and biologists measuring them have imperfect knowledge of the cues correlated with offspring fitness. Elaphrothrips tuberculatus sex allocation shows such gradual shifts with variation in conditions, but the shifts are asymmetric and similar in structure in both spring and summer, despite the seasonal difference in cues used by females. Thus, in spring, females tend to produce males only in relatively good patches where their offspring will become large adults, whereas females are produced in all patch types (Fig. 1). Similarly, in early summer, only relatively large females tend to produce males, whereas females of all sizes produce female offspring (Table 1). These data suggest that the sexallocation strategy of E. tuberculatus females involves primarily avoidance of producing males, the sex with higher variance in fitness, when offspring size is relatively uncertain. In other words, females may attempt to avoid the disastrous mistake of producing a brood of males that develop into small adults. Real (1980a, 1980b), Rubenstein (1982), and Seger and Brockmann (1987) have discussed the theoretical basis for the evolution of behavior that reduces uncertainty, and examples of selection for reduced uncertainty have been described for plant-pollinator interactions (Real, 1981) and foraging strategy (reviewed in Real and Caraco [1986]).

If uncertainty affects sex-ratio strategies, then individual and population sex-allocation patterns depend in a complex way upon frequency-dependent selection, the curves representing the covariation of male and female fitnesses with conditions (see Frank, $1987 a, 1987 c$ ), and the predictability, for females, of offspring fitness from conditions. When predictability is low, females are not expected to adjust sex-allocation ratios conditionally; this may be the situation in most animals. When fitness is moderately predictable or when predictability varies in space or time, females may adjust sex-allocation ratios asymmetrically, avoiding production of the sex with higher fitness variance where or when conditions are uncertain. As fitness becomes more predictable, females may conditionally adjust off- 
spring sex ratios in an increasingly symmetric manner, approaching the threshold relationship between all-male and allfemale production predicted by theory.

Fitness predictability may be a difficult variable to measure. However, it could be studied by among-species comparison of the types of cues used for conditional sex-ratio manipulation, in relation to the structure and symmetry of the empirical relationship between sex ratios and offspring fitness. Differences in predictability may help account for the wide variation among species in reports of the presence and strength of conditional sex-ratio manipulation (reviewed in Clutton-Brock and Iason [1986]). Thus far, the only other species for which evidence of conditional manipulation is available use sex-ratio cues (e.g., dominance rank in mammals, host size in parasitoid wasps) that appear unambiguous in their effects on offspring fitness (Charnov et al., 1981; Charnov, 1982; Clutton-Brock et al., 1984, 1986; Meikle et al., 1984; McFarland-Symington, 1987; Paul and Kuester, 1987).

\section{ACKNOWLEDGMENTS}

I thank R. D. Alexander, S. A. Frank, W. D. Hamilton, and R. Wrangham for helpful discussions and comments on earlier versions of the manuscript. J. Chanley, S. Frank, and L. Vawter provided expert field assistance, and the work was supported in part by an E. S. George Reserve Fellowship, a Rackham Predoctoral Fellowship and two Rackham Block Grants. I am grateful to R. Nussbaum for permission to live and work at the E. S. George Reserve.

\section{LiteratuRe Cited}

Ananthakrishnan, T. N. 1984. Bioecology of Thrips. Indira, Oak Park, MI.

BOOMSMA, J. J., AND J. A. ISAAKS. 1985. Energy investment and respiration in queens and males of Lasius niger (Hymenoptera: Formicidae). Behav. Ecol. Sociobiol. 18:19-27.

Bull, J. J. 1981. Sex ratio evolution when fitness varies. Heredity 46:9-26.

BURLEY, N. 1986. Sex-ratio manipulation in colorbanded populations of zebra finches. Evolution 40: 1191-1206.

Charnov, E. L. 1982. The Theory of Sex Allocation. Princeton Univ. Press, Princeton, NJ.

Charnov, E. L., R. L. Los-den Hartogh, W. T. Jones, AND J. VAN DEN ASSEM. 1981. Sex ratio evolution in a variable environment. Nature 289:27-33.
Clark, A. B. 1978. Sex ratio and local resource competition in a prosimian primate. Science 201:163165.

Clutton-Brock, T. H., S. D. Albon, AND F. E. GuINESS. 1984. Maternal dominance, breeding success and birth sex ratios in red deer. Nature 308: 358-360.

- 1986. Great expectations: Dominance, breeding success and offspring sex ratios in red deer. Anim. Behav. 34:460-471.

Clutton-Brock, T. H., AND G. R. IASON. 1986. Sex ratio variation in mammals. Quart. Rev. Biol. 61: 339-374.

Crespi, B. J. 1986a. Territoriality and fighting in a colonial thrips, Hoplothrips pedicularius, and sexual dimorphism in Thysanoptera. Ecol. Entomol. 11:119-130.

- $1986 b$. Size assessment and alternative fighting tactics in Elaphrothrips tuberculatus (Insecta: Thysanoptera). Anim. Behav. 34:1324-1335.

. 1987. Behavioral ecology of mycophagous Thysanoptera. Ph.D. Diss. Univ. Michigan, Ann Arbor.

- 1988a. Alternative male mating tactics in a thrips: Effects of sex ratio variation and body size. Amer. Midl. Natur. 119:83-92.

- $1988 b$. Risks and benefits of lethal male fighting in the colonial, polygynous thrips Hoplothrips karnyi (Insecta: Thysanoptera). Behav. Ecol. Sociobiol. 22:293-301.

FISHER, R. A. 1930 . The Genetical Theory of Natural Selection. Claredon, Oxford, U.K.

Fox, D. J., AND K. E. Guire. 1976. Documentation for MIDAS. Statistical Research Laboratory, Univ. Michigan, Ann Arbor.

FRANK, S. A. 1985. Hierarchical selection theory and sex ratios. II. On applying the theory, and a test with fig wasps. Evolution 39:949-964.

- 1986. Hierarchical selection theory and sex ratios. I. General solutions for structured populations. Theoret. Popul. Biol. 29:312-342.

- 1987a. Individual and population sex allocation patterns. Theoret. Popul. Biol. 31:47-74.

- 1987b. Demography and sex ratio in social spiders. Evolution 41:1267-1281.

-1987c. Variable sex ratio among colonies of ants. Behav. Ecol. Sociobiol. 20:195-201.

GrafeN, A. J. 1986. Split sex ratios and the evolutionary origins of eusociality. J. Theoret. Biol. 122: 95-121.

Hamilton, W. D. 1964a. The genetical evolution of social behaviour. I. J. Theoret. Biol. 7:1-16.

. 1964b. The genetical evolution of social behavior. II. J. Theoret. Biol. 7:17-52.

1967. Extraordinary sex ratios. Science 156: $477-488$.

- 1979. Wingless and fighting males in fig wasps and other species, pp. 167-220. In M. S. Blum and N. A. Blum (eds.), Sexual Selection and Reproductive Competition in Insects. Academic Press, N.Y.

HeRRE, E. A. 1985. Sex ratio adjustment in fig wasps. Science 228:896-898.

Kendall, M. G., ANd P. A. P. Moran. 1963. Geometrical Probablity. Hafner, N.Y.

LEwIS, T. 1973. Thrips, Their Biology, Ecology and Economic Importance. Academic Press, N.Y. 
McFarland-Symington, M. 1987. Sex ratio and maternal rank in wild spider monkeys: When daughters disperse. Behav. Ecol. Sociobiol. 20:421425.

MeIKLE, D. B., B. L. Tilford, AND S. H. Vessey. 1984. Dominance rank, secondary sex ratio, and reproduction of offspring in polygynous primates. Amer. Natur. 124:173-188.

MyerS, J. H. 1978. Sex ratio adjustment under food stress: Maximization of quality or numbers of offspring. Amer. Natur. 112:381-388.

NuNNEY, L. 1985. Female-biased sex ratios: Individual or group selection? Evolution 39:349-361.

Paul, A., AND J. Kuester. 1987. Sex ratio adjustment in a seasonally breeding primate species: Evidence from the Barbary macaque population at Affenburg Salem. Ethology 74:117-132.

REAL, L. A. 1980a. On uncertainty and the law of diminishing returns in evolution and behavior, $p$. 37-64. In J. E. R. Staddon (ed.), Limits to Action: The Allocation of Individual Behavior. Academic Press, N.Y.

. $1980 \mathrm{~b}$. Fitness, uncertainty, and the role of diversification in evolution and behavior. Amer. Natur. 115:623-638.

- 1981. Uncertainty and pollinator-plant interactions: The foraging strategies of bees and wasps on artificial flowers. Ecology 62:20-26.

Real, L. A., AND T. CaraCo. 1986. Risk and foraging in stochastic environments. Ann. Rev. Ecol. Syst. 17:371-390.

Rubenstein, D. I. 1982. Risk, uncertainty and evolutionary strategies, pp. 91-111. In King's College Sociobiology Group (eds.), Current Problems in Sociobiology. Cambridge Univ. Press, Cambridge, U.K.

SAS INSTITUTE. 1985. SAS User's Guide: Statistics, Version 5 Ed. SAS Inst., Inc., Cary, NC.
Seger, J., AND H. J. BrockmanN. 1987. What is bethedging? Oxford Surv. Evol. Biol. 4:182-211.

SHAw, R. F., AND J. D. MohlER. 1953. The selective advantage of the sex ratio. Amer. Natur. 87:337342.

StanNard, L. J. 1968. The thrips or Thysanoptera of Illinois. Illinois Nat. Hist. Surv. Bull. 29:215552.

TAYLOR, P. D. 1981. Intra-sex and inter-sex sib interactions as sex ratio determinants. Nature 227: 64-66.

-1985. A general mathematical model for sex allocation. J. Theoret. Biol. 112:799-818.

_. 1988. Inclusive fitness models with two sexes. Theoret. Popul. Biol. In press.

Trivers, R. L., AND D. E. Willard. 1973. Natural selection of parental ability to vary the sex ratio of offspring. Science 179:90-92.

WERREN, J. H. 1980. Sex ratio adaptation to local mate competition in a parasitic wasp. Science 208 : 1157-1159.

1983. Sex ratio evolution under local mate competition in a parasitic wasp. Evolution 37:116124.

-1984. A model for sex ratio selection in parasitic wasps: Local mate competition and host quality effects. Neth. J. Zool. 34:81-96.

Werren, J. H., and E. L. Charnov. 1978. Facultative sex ratios and population dynamics. Nature 272:349-350.

WERREN, J. H., AND P. D. TAYLOR. 1984. The effects of population recruitment on sex ratio selection. Amer. Natur. 124:143-148.

Williams, G. C. 1979. The question of adaptive sex ratio in outcrossed vertebrates. Proc. Roy. Soc. Lond. B 205:567-580.

Corresponding Editor: G. de Jong 